\title{
Laparoendoscopic single-site surgery (LESS) versus conventional laparoscopic surgery for adnexal preservation: a randomized controlled study
}

This article was published in the following Dove Press journal:

International Journal of Women's Health

9 March 2012

Number of times this article has been viewed

\author{
Yeon Jean Cho'* \\ Mi-La Kim ${ }^{2 *}$ \\ Soo Yoon Lee' \\ Hee Suk Lee' \\ Joo Myoung Kim' \\ Kwan Young Joo' \\ 'Department of Obstetrics \\ and Gynecology, Cheil General \\ Hospital and Women's Healthcare \\ Center, Kwandong University College \\ of Medicine, Seoul, Republic \\ of Korea; ${ }^{2}$ Department of Obstetrics \\ and Gynecology, CHA Gangnam \\ Medical Center, CHA University, \\ Seoul, Republic of Korea \\ *These authors contributed equally \\ to the paper
}

Correspondence: Joo Myoung Kim I-I 9 Mukjeoung-dong, Jung-gu, Cheil General Hospital and Women's

Healthcare Center, Kwandong University College of Medicine, Seoul 100-380,

Republic of Korea

Tel +82 220007 I 76

Fax +82 220007 I83

Email mila76@naver.com
Objective: To compare the operative outcomes, postoperative pain, and subsequent convalescence after laparoendoscopic single-site surgery (LESS) or conventional laparoscopic surgery for adnexal preservation.

Study design: From December 2009 to September 2010, 63 patients underwent LESS $(n=33)$ or a conventional laparoscopic surgery $(n=30)$ for cyst enucleation. The overall operative outcomes including postoperative pain measurement using the visual analog scale (VAS) were evaluated (time points 6, 24, and 24 hours). The convalescence data included data obtained from questionnaires on the need for analgesics and on patient-reported time to recovery end points. Results: The preoperative characteristics did not significantly differ between the two groups. The postoperative hemoglobin drop was higher in the LESS group than in the conventional laparoscopic surgery group $(P=0.048)$. Postoperative pain at each VAS time point, oral analgesic requirement, intramuscular analgesic requirement, and the number of days until return to work were similar in both groups.

Conclusion: In adnexa-preserving surgery performed in reproductive-age women, the operative outcomes, including satisfaction of the patients and convalescence after surgery, are comparable for LESS and conventional laparoscopy. LESS may be a feasible and a promising alternative method for scarless abdominal surgery in the treatment of young women with adnexal cysts

Keywords: laparoendoscopic single-site surgery, laparoscopic surgery, adnexal preservation, cyst, scar

\section{Introduction}

Recently, the number of laparoendoscopic single-site surgery (LESS) procedures performed has increased because of advancements in surgical instrumentation, cosmetic considerations and trends toward minimal invasiveness. ${ }^{1}$ The LESS procedure was developed due to the unique characteristics of the umbilicus, ie, it is the thinnest portion of the abdominal wall, does not have a muscle layer, and is naturally retracted. Hence, during the LESS procedure, there may be less tension during wound closure and relatively less scarring in the umbilicus than that in other areas. ${ }^{2}$

Many studies have been performed on LESS in the gynecologic field, including in gynecologic oncology. The use of LESS has been reported to be feasible and safe for ectopic pregnancy; adnexal surgery, including ovarian cyst enucleation; hysterectomy, including laparoscopic-assisted vaginal hysterectomy and total laparoscopic hysterectomy; and gynecologic malignancies. ${ }^{3-11}$ However, because few gynecologic studies have compared LESS and conventional laparoscopy, it is unclear whether LESS is truly better than the conventional surgical approach in reducing 
objective pain, as reflected by the objective pain scores for both procedures. ${ }^{12-15}$ Reproductive-age women diagnosed with a benign adnexal cyst have usually been treated with cyst enucleation to preserve their fertility. However, in LESS, it can be technically difficult to achieve the optimal traction-countertraction for enucleation and to control the bleeding from various foci. Hence, we designed the present study to specifically investigate differences in the operative outcomes, postoperative pain, and subsequent convalescence after LESS and conventional laparoscopic surgery for unilateral cyst enucleation in reproductive-age women with benign adnexal cysts.

\section{Materials and methods}

Our study was a prospective randomized controlled study involving patients who underwent surgical intervention involving LESS or conventional laparoscopic surgery for cyst enucleation of a unilateral benign adnexal mass. The study period was December 2009 to September 2010, and the study involved patients from Cheil General Hospital and Women's Healthcare Center, Seoul, Korea. During the study period, 80 patients met the inclusion criteria and agreed to be enrolled in the study. Forty patients were alternately assigned to undergo LESS, and 40 were assigned to undergo conventional laparoscopic surgery.

The inclusion criteria were as follows: aged between 18 and 45 years; premenopausal status; presence of a unilateral adnexal mass, the largest diameter of the unilateral adnexal mass ranging between $4 \mathrm{~cm}$ and $10 \mathrm{~cm}$ in imaging studies; and normal cancer antigen (CA)-125 levels. The exclusion criteria were as follows: evidence of pelvic or ovarian endometriosis; previous history of pelvic inflammatory disease; suspicion of malignancy or pelvic adhesion; and postmenopausal status. To avoid any possible confounder in the quantification of postoperative pain, patients who needed additional wound extension for specimen removal were excluded from the study. In addition, a patient who wanted to postoperatively control her pain with patient-controlled analgesia (PCA) was excluded from the study.

The study protocol was approved by the Institutional Review Board of the Cheil General Hospital and Women's Healthcare Center. All the patients were adequately informed of the possible risks and benefits of both LESS and conventional laparoscopic surgery. All study participants signed a written consent agreeing to undergo cyst enucleation by LESS or the conventional method and, if necessary, to allow the use of an additional ancillary port during LESS. The patients were randomly assigned to undergo LESS or conventional laparoscopic surgery. Three experienced surgeons (YJ Cho, JM Kim and ML Kim) were involved in the protocol, and in the treatment procedure. At the end of the surgery, intraoperative data such as the trocar-introduction time, operation time, intraoperative and postoperative complications, and number of conversions to laparotomy were recorded. During the convalescence period, oral feeding was started on postoperative day 1 . Intramuscular or oral analgesics were provided only on the patient's request. The visual analog scale (VAS), scored from 0 to 10 (with " 0 " being "no pain" and " 10 " being "agonizing pain") was self-reported at 6, 24, and 48 hours after surgery. Follow-up information about the use of analgesics and patient-reported time to recovery end points were obtained from office visits at 4 weeks after the surgery via a modified questionnaire (Appendix A) that was adapted from those used in a previous study and was administered by the physician members of the research team. ${ }^{16}$

Statistical analysis was performed with SPSS version 15.0 (SPSS, Inc, Chicago, IL) by using Student's $t$-test, Fisher's exact test, and the Chi-square test. A $P$-value of less than 0.05 was considered to be statistically significant.

\section{Operative techniques}

The patient was placed in the lithotomy position. The surgeon stood on the left side of the patient. The first assistant

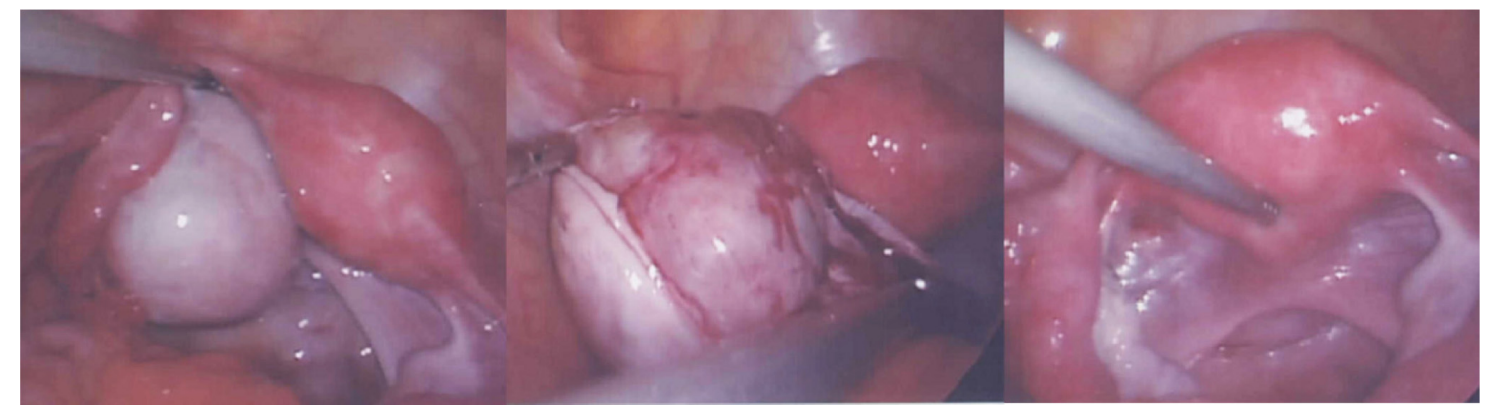

Figure I Laparoendoscopic single-site surgery (LESS) for adnexal preservation (intraoperative view). 
Table I Demographic data of patients

\begin{tabular}{llll}
\hline Characteristics & $\begin{array}{l}\text { Laparoendoscopic single-site surgery } \\
(\mathbf{n}=\mathbf{3 3})\end{array}$ & $\begin{array}{l}\text { Conventional laparoscopic surgery } \\
(\mathbf{n}=\mathbf{3 0})\end{array}$ & $\begin{array}{c}P \text {-value } \\
\text { Age (years) }\end{array}$ \\
Gravidity $(\mathrm{n})$ & $29.5 \pm 6.2$ & $31.1 \pm 7.2$ & $\mathrm{NS}$ \\
Parity $(\mathrm{n})$ & $0.9 \pm 1.5$ & $0.8 \pm 1.3$ & $\mathrm{NS}$ \\
Body mass index $\left(\mathrm{kg} / \mathrm{m}^{2}\right)$ & $0.3 \pm 0.8$ & $0.5 \pm 0.8$ & $\mathrm{NS}$ \\
Largest diameter of adnexal mass $(\mathrm{cm})$ & $21.4 \pm 3.2$ & $22.5 \pm 3.3$ & $\mathrm{NS}$ \\
Pathologic findings $(\mathbf{n})$ & $6.6 \pm 1.6$ & $7.0 \pm 1.7$ & $\mathrm{NS}$ \\
Mature cystic teratoma & & & $\mathrm{NS}$ \\
Serous cystadenoma & $22(66.7 \%)$ & $19(63.3 \%)$ & $5(16.7 \%)$ \\
Mucinous cystadenoma & $4(12.1 \%)$ & $2(6.7 \%)$ & \\
Paratubal cyst & $3(9.1 \%)$ & $4(13.3 \%)$ & $\mathrm{NS}$ \\
History of previous abdominopelvic surgery & $4(12.1 \%)$ & $5(16.7 \%)$ & \\
\hline
\end{tabular}

stood on the right side of the patient to operate the scope. In the case of LESS, the patients underwent surgery through a single $2-2.5 \mathrm{~cm}$ vertical umbilical incision, performed via the open Hasson technique. We used a homemade wound retractor and a surgical glove as the single-port device. The distal ring of an Alexis ${ }^{\circledR}$ retractor (Applied Medical, Santa Rancha Margarita, CA) was used as the intra-abdominal portion of a commercialized wound retractor, and it was rolled up with the wrist portion of a powder-free latex surgical glove (GammexPF, 7-0; Ansell Ltd, Victoria, Australia). The multiple fingers of the glove functioned as a multiport for the laparoscopic instruments and the scope.

We used a rigid 0 or 30 degree, $5 \mathrm{~mm}$ or $10 \mathrm{~mm}$ laparoscope and standard rigid $5 \mathrm{~mm}$ laparoscopic instruments. The homemade single-port device was inserted into the umbilicus, and two or three $5 \mathrm{~mm}$ sheaths and one $10 \mathrm{~mm}$ sheath were inserted through the open fingertip portions of the surgical glove and tied with 6-0 silk ligatures to prevent gas leakage. Next, carbon dioxide was insufflated to maintain intra-abdominal pressure at $12 \mathrm{mmHg}$. Once the laparoscope and instruments were in place, the subsequent procedure was similar to the one performed in conventional laparoscopic surgery (Figure 1). Adnexal specimens were extracted with an EndoPouch (Ethicon Endo-Surgery, Cincinnati, $\mathrm{OH}$ ) via the umbilicus. The peritoneum and fascia were approximated and closed layer by layer with 2-0 Vicryl sutures.

For conventional laparoscopy, the $10 \mathrm{~mm}$ laparoscope was introduced into the abdominal cavity through the umbilicus, and three $5 \mathrm{~mm}$ accessory trocars were suprapubically inserted under direct vision. All the specimens were extracted using the EndoPouch via the umbilicus under the guidance of a $5 \mathrm{~mm}$ laparoscope.

\section{Results}

Among the 80 patients selected, 63 were eligible for analysis. In the LESS group, seven patients were excluded because three had deep infiltrating pelvic endometriosis and needed resection of those lesions, one was diagnosed with ovarian endometrioma, one was lost to follow-up, and two needed an additional ancillary port for adhesiolysis and bleeding control. In the conventional laparoscopic surgery group, ten patients were excluded because one had severe pelvic adhesion, six had pelvic and/or ovarian endometriosis, and three had incompletely answered the self-reported questionnaires. These ten excluded patients were successfully treated by the surgical procedure appropriate for their condition. The characteristics of the patients are summarized in Table 1. Both the groups were comparable in terms of demographic

Table 2 Perioperative outcomes of the patients

\begin{tabular}{lll}
\hline Variables & $\begin{array}{l}\text { Laparoendoscopic single-site surgery } \\
(\mathbf{n}=\mathbf{3 3})\end{array}$ & $\begin{array}{l}\text { Conventional laparoscopic surgery } \\
(\mathbf{n}=\mathbf{3 0})\end{array}$ \\
\hline Operation time, min & $42.1 \pm 18.2$ & $36.3 \pm 15.0$ \\
Conversion to laparotomy & $0(0 \%)$ & $0(0 \%)$ \\
Preoperative Hb level, g/dL & $12.1 \pm 0.8$ & $12.6 \pm 0.8$ \\
Hemoglobin drop, g/dL & $2.0 \pm 0.7$ & $1.7 \pm 0.6$ \\
Postoperative complications & $2(6.1 \%)$ & $0(0 \%)$ \\
Paralytic ileus & $\mathrm{I}$ & 0 \\
Delayed ovarian bleeding & $\mathrm{I}$ & 0.048 \\
\hline
\end{tabular}

Abbreviation: $\mathrm{Hb}$, hemoglobin. 
Table 3 Pain and convalescent outcomes

\begin{tabular}{|c|c|c|c|}
\hline Variables & $\begin{array}{l}\text { Laparoendoscopic single-site surgery } \\
(\mathrm{n}=33)\end{array}$ & $\begin{array}{l}\text { Conventional laparoscopic surgery } \\
(n=30)\end{array}$ & $P$-value \\
\hline VAS score after 6 hours & $4.5 \pm 2.1$ & $4.3 \pm 2.1$ & NS \\
\hline VAS score after 24 hours & $3.3 \pm 1.9$ & $3.5 \pm 2.0$ & NS \\
\hline VAS score after 48 hours & $2.3 \pm 1.4$ & $2.2 \pm 1.6$ & NS \\
\hline $\begin{array}{l}\text { Required intramuscular analgesic dose } \\
\text { within } 24 \text { hours }\end{array}$ & $0.4 \pm 0.7$ & $0.3 \pm 0.5$ & NS \\
\hline Required oral analgesic dose & $1.9 \pm 3.5$ & $1.9 \pm 4.0$ & NS \\
\hline Days on oral analgesic use after discharge & $1.3 \pm 1.8$ & $0.9 \pm 1.5$ & NS \\
\hline Days to return to work & $7.4 \pm 3.8$ & $6.4 \pm 3.5$ & NS \\
\hline $\begin{array}{l}\text { Patient-reported scar satisfaction scale } \\
\text { (I-5 scale) }\end{array}$ & $\begin{array}{l}4.2 \pm 1.0 \\
(2-5, \text { median } 5.0)\end{array}$ & $\begin{array}{l}4.6 \pm 1.0 \\
(2-5, \text { median } 5.0)\end{array}$ & NS \\
\hline $\begin{array}{l}\text { Percentage that would recommend } \\
\text { to a friend or family member }\end{array}$ & $100 \%$ & $96.7 \%$ & NS \\
\hline
\end{tabular}

Abbreviation: VAS, visual analog scale.

characteristics and the final pathologic results. The perioperative outcomes are shown in Table 2. The mean operation times were 42.1 minutes and 36.3 minutes for the LESS group and conventional laparoscopic surgery group, respectively. No patient from either of the groups required conversion to laparotomy. The mean hemoglobin drop was $2.0 \mathrm{~g} / \mathrm{dL}$ in the LESS group and was thus higher than that in the conventional laparoscopic surgery group $(P=0.048)$. However, no patient required a blood transfusion in the study groups.

Postoperative complications occurred in two patients in the LESS group. One patient experienced abdominal distension and pain after oral intake and was diagnosed with paralytic ileus by abdominal radiography. After conservative management, her bowel function was restored spontaneously. Another patient experienced delayed ovarian bleeding from the enucleation site. Her initial hemoglobin level was $13.3 \mathrm{~g} / \mathrm{dL}$; at postoperative day 3 , her hemoglobin level was $7.5 \mathrm{~g} / \mathrm{dL}$. On transvaginal ultrasonography, a $7 \mathrm{~cm}$ hematoma was detected at the enucleation site. The patient had no symptoms or signs of acute bleeding and refused transfusion for anemia correction. On a follow-up visit 2 weeks after the surgery, the size of the hematoma had decreased to $5 \mathrm{~cm}$ and was found to have completely resolved in 6 weeks after surgery.

The data for postoperative pain, including the VAS score and the use of additional analgesics after surgery, are shown in Table 3. There were no statistical differences in the VAS scores obtained at 6,24 , and 48 hours after surgery. Moreover, the mean number of days of oral analgesic use after discharge was only 1.3 days and 0.9 days in the LESS and conventional surgery groups, respectively. There was no difference in the number of days until return to work. The self-reported scar satisfaction scale results were similar for both groups. Most of the patients stated that they would recommend the procedure to a friend or a family member undergoing laparoscopic adnexa-preserving surgery.

\section{Conclusion}

Ever since laparoscopic surgery was introduced in the gynecologic field, minimally invasive surgery has steadily evolved toward progressively less invasive techniques. Currently, there is an increasing interest in LESS. ${ }^{17}$

There are many benefits of LESS as compared to conventional multiport laparoscopic surgery. LESS may result in better cosmesis owing to the relatively hidden umbilical scar, obviation of the use of ancillary ports, and use of the open Hasson technique; therefore, the injury rates by the Verres needle and primary trocar are low. Additionally, inferior epigastric vessel injury, postoperative wound infection, and hernia formation are potentially reduced. Compared to the conventional $5 \mathrm{~mm}$ or $11 \mathrm{~mm}$ trocar incisions, a relatively large incision on the umbilicus facilitates easier specimen removal. ${ }^{11}$ Some studies involving retrospective comparsions of hysterectomy have shown that the postoperative pain and narcotic use is less than conventional laparoscopic hysterectomy. ${ }^{13,14}$ To our knowledge, a prospective study focusing on only cyst enucleation has not yet been published.

At present, several studies have been published regarding LESS treatment of adnexal disease and have shown that the results for LESS are comparable to those for conventional laparoscopic surgery. Most of these studies have compared or listed the perioperative outcomes of adnexal surgery procedures such as salpingo-oophorectomy or salpingectomy. $3,6,7,11-13,18-24$ However, in our study, we compared the perioperative results including return to work and postoperative satisfaction for LESS and conventional laparoscopic surgery performed only 
for cyst enucleation in reproductive-age women with unilateral adnexal cysts. As reproductive-age women are concerned about the cosmetic problems clinicians have to consider LESS, but little is known about the safety of adnexa-preserving surgery involving LESS.

One of the current problems with LESS is the crowding of instruments at the point of entry into the abdomen. This problem can be partially offset by using articulating instruments with varying curvatures. In all our procedures, we used only a conventional scope and instruments for LESS. The operative time, complications, and postoperative convalescence were comparable between both groups. However, if there is a concern about the high cost of flexible laparoscopic instruments, we think that conventional instruments, which are cost effective, could be safely used. The use of a 30-degree scope or digital endoscope (Olympus EndoEYE) would eliminate the cumbersome right-angle light pillar and the camera head, thereby minimizing the possibility of crowding at the entry site. Furthermore, its superior digital image quality owing to the $5 \mathrm{~mm}$ telescope would provide excellent visualization. ${ }^{25}$

LESS and conventional laparoscopic surgery were comparable in terms of pain. No statistical differences were observed between VAS scores or the requirement for analgesics (intramuscular or oral) for both groups. In addition, given the aforementioned facts, we used a specific convalescence questionnaire, which was previously used, focused on patient-reported time to specific, easily recalled postoperative events. The patient-reported scar satisfaction scale results were high for both groups, and most of the patients experienced complete recovery and returned to work within 7 days. Although this study was a prospective randomized controlled study, the study population was small. We think that LESS is safe and feasible for women who need adnexapreserving surgery, but we could not find major advantages of this method in terms of early convalescence and postoperative pain. Large prospective randomized studies are required to establish the advantages of adnexa-preserving surgery involving LESS over those of adnexa-preserving surgery involving conventional laparoscopic surgery. However, the postoperative hemoglobin drop was statistically higher in the LESS group $(2.0 \pm 0.7 \mathrm{~g} / \mathrm{dL})$ than in the conventional surgery group $(1.7 \pm 0.6 \mathrm{~g} / \mathrm{dL})$. Conversely, none of the patients required blood transfusion, and we think that this difference in postoperative hemoglobin drop can be reduced if we gain more experience in performing LESS.

To our knowledge, this is the first study involving a prospective comparison between LESS and conventional laparoscopic surgery performed for adnexal preservation. We conclude that performing LESS is safe and feasible in selected female patients diagnosed with a benign adnexal mass requiring fertility-preserving surgery.

\section{Disclosure}

The authors report no conflicts of interest in this work.

\section{References}

1. Jeon $\mathrm{HG}$, Jeong W, Oh CK, et al. Initial experience with 50 laparoendoscopic single site surgeries using a homemade, single port device at a single center. J Urol. 2010;183(5):1866-1871.

2. Kim TJ. Single-port access (SPA) laparoscopic surgery. Korean $J$ Gynecol Endosc Minim Invasive Surg. 2009;21(1):27-30. Korean.

3. Yoon BS, Park H, Seong SJ, Park CT, Park SW, Lee KJ. Single-port laparoscopic salpingectomy for the surgical treatment of ectopic pregnancy. J Minim Invasive Gynecol. 2010;17(1):26-29.

4. Lim MC, Kim TJ, Kang S, Bae DS, Park SY, Seo SS. Embryonic natural orifice transluminal endoscopic surgery (E-NOTES) for adnexal tumors. Surg Endosc. 2009;23(11):2445-2449.

5. Kim TJ, Lee YY, Kim MJ, et al. Single port access laparoscopic adnexal surgery. J Minim Invasive Gynecol. 2009;16(5):612-615.

6. Fagotti A, Fanfani F, Rossitto C, et al. Laparoendoscopic single-site surgery for the treatment of benign adnexal disease: a prospective trial. Diagn Ther Endosc. 2010;2010:108258.

7. Escobar PF, Bedaiwy MA, Fader AN, Falcone T. Laparoendoscopic single-site (LESS) surgery in patients with benign adnexal disease. Fertil Steril. 2010;93(6):2074.e7-e10.

8. Lee YY, Kim TJ, Kim CJ, et al. Single-port access laparoscopic-assisted vaginal hysterectomy: a novel method with a wound retractor and a glove. J Minim Invasive Gynecol. 2009;16(4):450-453.

9. Koyanagi T, Motomura S. Transumbilical single-incision laparoscopic surgery: application to laparoscopically assisted vaginal hysterectomy. Arch Gynecol Obstet. 2011;283(2):305-309.

10. Jung YW, Kim YT, Lee DW, et al. The feasibility of scarless singleport transumbilical total laparoscopic hysterectomy: initial clinical experience. Surg Endosc. 2010;24(7):1686-1892.

11. Fader AN, Escobar PF. Laparoendoscopic single-site surgery (LESS) in gynecologic oncology: technique and initial report. Gynecol Oncol. 2009;114(2):157-161.

12. Lee YY, Kim TJ, Kim CJ, et al. Single port access laparoscopic adnexal surgery versus conventional laparoscopic adnexal surgery: a comparison of peri-operative outcomes. Eur J Obstet Gynecol Reprod Biol. 2010;151(2):181-184.

13. Fagotti A, Battoni C, Vizzielli G, et al. Postoperative pain after conventional laparoscopy and laparoendoscopic single site surgery (LESS) for benign adnexal disease: a randomized trial. Fertil Steril. 2011;96(1):255-259.e2.

14. Kim TJ, Lee YY, Cha HH, et al. Single-port-access laparoscopicassisted vaginal hysterectomy versus conventional laparoscopic-assisted vaginal hysterectomy: a comparison of perioperative outcomes. Surg Endosc. 2010;24(9):2248-2252.

15. Yim GW, Jung YW, Paek J, et al. Transumbilical single-port access versus conventional total laparoscopic hysterectomy: surgical outcomes. Am J Obstet Gynecol. 2010;203(1):26.e1-e6.

16. Canes D, Berqer A, Aron M, et al. Laparo-endoscopic single site (LESS) versus standard laparoscopic left donor nephrectomy: matched-pair comparison. Eur Urol. 2010;57(1):95-101.

17. Ramirez PT. Single-port laparoscopic surgery: is a single incision the next frontier in minimally invasive gynecologic surgery? Gynecol Oncol. 2009;114(2):143-144.

18. Fagotti A, Fanfani F, Marocco F, Rossitto C, Gallotta V, Scambia G. Laparoendoscopic singlesite surgery (LESS) for ovarian cyst enucleation: report of first 3 cases. Fertil Steril. 2009;92(3):1168.e13-e16. 
19. Escobar PF, Fader AN, Paraiso MF, Kaouk JH, Falcone T. Roboticassisted laparoendoscopic singlesite surgery in gynecology: initial report and technique. J Minim Invasive Gynecol. 2009;16(5):589-591.

20. Escobar PF, Starks DC, Fader AN, Barber M, Rojas-Espalliat L. Single-port risk-reducing salpingo-oophorectomy with and without hysterectomy: surgical outcomes and learning curve analysis. Gynecol Oncol. 2010;119(1):43-47.

21. Fader AN, Rojas-Espaillat L, Ibeanu O, Grumbine FC, Escobar PF. Laparoendoscopic single-site surgery (LESS) in gynecology: a multiinstitutional evaluation. Am J Obstet Gynecol. 2010;203(5):501.e1-e6.

22. Marocco F, Fanfani F, Rossitto C, Gallotta V, Scambia G, Fagotti A. Laparoendoscopic single-site surgery for fertility-sparing staging of border line ovarian tumors: initial experience. Surg Laparosc Endosc Percutan Tech. 2010;20(5):e172-e175.
23. Fagotti A, Fanfani F, Marocco F, et al. Laparoendoscopic single-site surgery for the treatment of benign adnexal diseases: a pilot study. Surg Endosc. 2011;25(4):1215-1221.

24. Fagotti A, Rossitto C, Marocco F, et al. Perioperative outcomes of laparoendoscopic single-site surgery (LESS) Versus conventional laparoscopy for adnexal disease: a case-control study. Surg Innov. 2011;18(1):29-33.

25. Desai MM, Stein R, Rao P, et al. Embryonic natural orifice transumbilical endoscopic surgery (E-NOTES) for advanced reconstruction: initial experience. Urology. 2009;73(1):182-187. 


\section{Appendix A}

\section{Patient questionnaire}

1. How many days or weeks did you require oral pain killers after being discharged from the hospital?

2. How many days or weeks before you went back to work after being discharged from the hospital?

3. How would you rate your surgical scar(s) on a scale of $1-5$, with 5 being delighted and 1 being very displeased?

4. Would you recommend that a friend or family member in a similar situation undergo your procedure? Yes/No.

\section{Publish your work in this journal}

The International Journal of Women's Health is an international, peerreviewed open-access journal publishing original research, reports, reviews and commentaries on all aspects of women's healthcare including gynecology, obstetrics, and breast cancer. Subject areas include: Chronic conditions (migraine headaches, arthritis, osteoporosis);
Dovepress

Endocrine and autoimmune syndromes; Sexual and reproductive health; Psychological and psychosocial conditions. The manuscript management system is completely online and includes a very quick and fair peer-review system. Visit http://www.dovepress.com/ testimonials.php to read real quotes from published authors. 